\title{
Effect of dietary omega-3 polyunsaturated fatty acids on heart rate and heart rate variability in animals susceptible or resistant to ventricular fibrillation
}

\author{
George E. Billman ${ }^{1,2}$ * \\ Department of Physiology and Cell Biology, The Ohio State University, Columbus, OH, USA \\ ${ }^{2}$ Davis Heart and Lung Research Institute, The Ohio State University, Columbus, OH, USA
}

Edited by:

Hester M. Den Ruijter, University of

Amsterdam, Netherlands

\section{Reviewed by:}

Carmen Valenzuela, Instituto de Investigaciones Biomédicas CSIC-UAM, Spain

Antonius Baartscheer, Academic

Medical Center, Netherlands

\section{${ }^{*}$ Correspondence:}

George E. Billman, Department of Physiology and Cell Biology, The Ohio State University, 304 Hamilton Hall, 1645 Neil Avenue, Columbus, $\mathrm{OH}$ 43210-1218, USA.

e-mail: billman.1@osu.edu
The consumption of omega-3 polyunsaturated fatty acids ( $n-3$ PUFAs) has been reported to reduce cardiac mortality following myocardial infarction as well as to decrease resting heart rate (HR) and increase HR variability (HRV). However, it has not been established whether $n-3$ PUFAs exhibit the same actions on HR and HRV in individuals known to be either susceptible or resistant to ventricular fibrillation (VF). Therefore, HR and HRV (high frequency and total R-R interval variability) were evaluated before and 3 months after $n-3$ PUFA treatment in dogs with healed myocardial infarction that were either susceptible (VF+, $n=31$ ) or resistant (VF-, $n=31$ ) to ventricular tachyarrhythmias induced by a 2-min coronary artery occlusion during the last minute of a submaximal exercise test. HR and $\mathrm{HRV}$ were evaluated at rest, during submaximal exercise and in response to acute myocardial ischemia at rest before and after either placebo ( $1 \mathrm{~g} /$ day, corn oil, $\mathrm{VF}+, n=9 ; \mathrm{VF}-n=8$ ) or $n-3$ PUFA (docosahexaenoic acid + eicosapentaenoic acid ethyl esters, 1-4 g/day, VF+, $n=22$; VF-,$n=23$ ) treatment for 3 months. The $n-3$ PUFA treatment elicited similar increases in red blood cell membrane, right atrial, and left ventricular $n-3$ PUFA levels in both the VF+ and VF- dogs. The n-3 PUFA treatment also provoked similar reductions in baseline HR and increases in baseline HRV in both groups that resulted in parallel shifts in the response to either exercise or acute myocardial ischemia (that is, the change in these variables induced by physiological challenges was not altered after $n-3$ PUFA treatment). These data demonstrate that dietary $n-3$ PUFA decreased HR and increased HRV to a similar extent in animals known to be prone to or resistant to malignant cardiac tachyarrhythmias.

Keywords: parasympathetic nervous system, exercise, myocardial ischemia, fish oil, docosahexaenoic acid, eicosapentaenoic acid

\section{INTRODUCTION}

There is strong association between abnormal cardiac autonomic regulation and an increased risk for sudden cardiac death (Billman, 2009). In particular, both patients and animals that exhibit large reductions in cardiac parasympathetic activity coupled with an enhanced sympathetic activation following myocardial infarction have an increased incidence of malignant ventricular tachyarrhythmias and sudden cardiac death (Billman, 2009). Therefore, therapeutic interventions that improve cardiac balance could protect against sudden death in high-risk patient populations.

A number of experimental and clinical studies report that dietary omega- 3 polyunsaturated fatty acids ( $n-3$ PUFAs; Christensen et al., 1999; Christensen and Schmidt, 2007; Christensen, 2011) or the acute intravenous administration (Billman et al., 1994) of these lipids can both lower resting heart rate (HR) and increase resting HR variability (HRV), data consistent with an enhanced baseline cardiac parasympathetic tone (Billman, $2009,2011)$. It has been proposed that the cardiovascular benefits ascribed to dietary $n-3$ PUFAs could result, at least in part, from these reductions in HR and the corresponding putative improvements in cardiac autonomic balance (Christensen et al., 1999; Christensen and Schmidt, 2007; Christensen, 2011) or intrinsic rate (Laustiola et al., 1986; Kang and Leaf, 1994; Harris et al., 2006; Verkerk et al., 2009; Billman and Harris, 2011). Billman and Harris (2011) recently demonstrated that $n-3$ PUFA supplements decrease baseline HR and increased baseline HRV in animals with healed myocardial infarctions but did not alter the response to physiological challenges (exercise or acute myocardial ischemia). However, they did not determine whether the $n-3$ PUFA treatment elicited different actions in animals that were known to be either resistant or susceptible to ventricular fibrillation (VF). It is possible that those individuals with the greatest impairment in cardiac autonomic regulation (and at the greatest risk for adverse cardiac events) may exhibit larger changes in HRV following $n-3$ PUFA treatment than patients with well-preserved autonomic function.

It was, therefore, the purpose of the present study to evaluate the effects of dietary $n-3$ PUFAs (1-4g/day for 3 months) on the HR and the HRV responses to physiological stressors (exercise or acute myocardial ischemia) in dogs with healed myocardial 
infarctions that had been identified as either being susceptible $(\mathrm{VF}+)$ or resistant $(\mathrm{VF}-)$ to the induction of malignant ventricular tachyarrhythmias. In particular, the hypothesis that dietary $n-3$ PUFA supplements would produce different HR and HRV responses to physiologic challenges in $\mathrm{VF}+$ and $\mathrm{VF}-$ dogs was tested.

\section{MATERIALS AND METHODS}

All the animal procedures were approved by the Ohio State University Institutional Animal Care and Use Committee and conformed to the Guide for the Care and Use of Laboratory Animals published by the US National Institutes of Health (NIH publication No. 85-23, revised 1996).

Archived data from 62 heartworm free mixed breed dogs (2to 3 -year-old, male $n=20$, female $n=42$ ) weighing $19.9 \pm 0.4 \mathrm{~kg}$ (range 12.5-25.8 kg) that were part of an ongoing investigation of the cardiovascular effects of dietary $n-3$ PUFA (Billman et al., 2010, 2012; Billman and Harris, 2011) were used in the present study. The sole selection criterion was an ECG signal of sufficient quality to determine HRV both at baseline and in response to physiological challenges (i.e., exercise or acute myocardial ischemia).

\section{SURGICAL PREPARATION}

The animals were anesthetized and instrumented to measure a ventricular electrogram (from which HR and HRV were subsequently determined) and left circumflex coronary artery blood flow as previously described (Billman et al., 1982; Schwartz et al., 1984; Billman, 2006). A hydraulic vascular occluder (Model OC3, In vivo Metric, Healdsburg, CA, USA) was placed around the left circumflex coronary artery and used to induce acute myocardial ischemia for the coronary occlusion experiments described below (see the HRV protocols). The left anterior descending coronary artery was also isolated during the instrumentation surgery and a two-stage occlusion of this artery was then performed approximately one-third the distance from its origin in order to produce an anterior wall myocardial infarction $[\sim 16 \%$ of left ventricular mass (Billman, 2006]. This vessel was partially occluded for $20 \mathrm{~min}$ and then tied off. The dogs were given analgesic, antibiotic, and anti-arrhythmic therapy to alleviate post-operative pain, to prevent post-operative infection, and to reduce acute arrhythmias associated with the myocardial infarction as has been previously described (Billman et al., 1982; Schwartz et al., 1984; Billman, 2006).

\section{EXERCISE PLUS ISCHEMIA TEST}

The studies began 3-4 weeks after the production of the myocardial infarction. The susceptibility to VF was tested as previously described (Billman et al., 1982; Schwartz et al., 1984; Billman, 2006). Briefly, the animals ran on a motor-driven treadmill while workload progressively increased until a $\mathrm{HR}$ of $70 \%$ of maximum (approximately 210 beats/min) had been achieved. During the last minute (on average during the 18th minute) of exercise, the left circumflex coronary artery was occluded, the treadmill stopped, and the occlusion maintained for an additional minute (total occlusion time $=2 \mathrm{~min}$ ). The exercise plus ischemia test reliably induced ventricular flutter that rapidly deteriorated into VF.
Therefore, large defibrillation electrodes (Adult Stat-padz, Zoll Medical, Burlington, MA, USA) were placed across the animal's chest so that electrical defibrillation (Zoll M series defibrillator) could be achieved with a minimal delay but only after the animal was unconscious (10-20 s after the onset of VF). The occlusion was immediately released if VF occurred. In the present study, 31 dogs developed VF (susceptible, VF+) while 31 did not (resistant, $\mathrm{VF}-$ ).

\section{HEART RATE VARIABILITY PROTOCOLS}

Heart rate variability was calculated using a Delta-Biometrics vagal tone monitor triggering off the electrocardiogram $\mathrm{R}-\mathrm{R}$ interval (Urbana-Champaign, IL, USA). This device employs the timeseries signal processing techniques as developed by Porges to estimate the amplitude of respiratory sinus arrhythmia [the high frequency, HF component of R-R interval variability (Porges, 1986)]. Details of this analysis have been described previously (Billman and Hoskins, 1989; Billman and Dujardin, 1990; Houle and Billman, 1999). Data were averaged over $30 \mathrm{~s}$ intervals either during exercise or the coronary occlusion. The following indices of HRV were determined: Vagal Tone Index, the HF $(0.24-1.04 \mathrm{~Hz})$ component of R-R interval variability, and the $\mathrm{SD}$ of the $\mathrm{R}-\mathrm{R}$ intervals (a marker of total variability) for the same $30 \mathrm{~s}$ time periods.

First, over the period of 3-5 days, the dogs learned to run on a motor-driven treadmill. The cardiac response to submaximal (i.e., $60-70 \%$ of maximal HR) exercise was then evaluated as follows: exercise lasted a total of $18 \mathrm{~min}$ with workload increasing every 3min. The protocol began with a 3-min "warm-up" period, during which the dogs ran at $4.8 \mathrm{kph}$ at $0 \%$ grade. The speed was then increased to $6.4 \mathrm{kph}$, and the grade increased every $3-\min (0,4$, 8,12 , and $16 \%$ ). The submaximal exercise test was repeated three times (one/day). On a subsequent day, with the dogs lying quietly unrestrained on a table, a 2-min left circumflex coronary occlusion was made. Left circumflex blood flow, HR, and HRV were monitored continuously throughout the exercise or occlusion studies. The submaximal exercise and the coronary occlusion at rest studies were performed both before and after 3 months of treatment with either placebo ( $1 \mathrm{~g} /$ day corn oil) or daily $n-3$ PUFA capsules (1-4 g/day).

\section{DIETARY OMEGA-3 POLYUNSATURATED FATTY ACID PROTOCOL}

The dogs were placed on a diet that did not contain any $n-3$ PUFAs (Harlan Teklad, Harlan Laboratories, Inc., Indianapolis, IN, USA) beginning 1 week prior to the instrumentation surgery and were maintained on this diet until the end of the study ( $\sim 4$ months). After the pre-treatment data collection (3-4 weeks after the surgery), the dogs were then randomly assigned to the following groups: placebo ( $n=17: \mathrm{S}, n=9 ; \mathrm{R}, n=8) ; n-3$ PUFA (1-4 g/day, $n=45: \mathrm{S}, n=22 ; \mathrm{R}, n=23$ ). The dogs were given supplements similar to those used in the GISSI-Prevenzione study (Di Stasi et al., 2004). The $n-3$ PUFA group received $465 \mathrm{mg}$ ethyl eicosapentaenoate, EPA + ethyl docosahexaenoate, DHA, $375 \mathrm{mg}$ per $1 \mathrm{~g}$ capsule $\left(\right.$ Lovaza $^{\circledR}$, GlaxoSmithKline, Research Triangle Park, NC, USA). The placebo was corn oil ( $1 \mathrm{~g}, 58 \%$ linoleic acid $+28 \%$ oleic acid). The capsules were given per os prior to the daily feeding (between 8:00 and 10:00 a.m. each day, 7 days per week for 3 months). 


\section{RED BLOOD CELL AND CARDIAC TISSUE FATTY ACID ANALYSIS}

Fasting blood samples $(5 \mathrm{ml})$ were drawn into EDTA tubes from a cephalic vein between 8:00 and 9:00 a.m. 1 day prior to the initiation of the treatment (placebo or $n-3$ PUFA) and when tissue was harvested at the end of the study ( $\sim 14$ weeks after the treatment began). Right atrial and left ventricular tissue were obtained when the hearts were harvested; the tissue and red blood cells (RBC) were flash frozen in liquid nitrogen; and stored at $-80^{\circ} \mathrm{C}$ for future analysis.

Red blood cell and phospholipids from cardiac tissue were analyzed for fatty acid composition using previously described techniques (Bligh and Dyer, 1959; Morrison and Smith, 1964). The samples were analyzed by gas chromatography using a GC2010FID (Shimadzu Corporation, Columbia, MD, USA) equipped with a 100-mm capillary column (SP-2560, Supelco, Bellefonte, PA, USA). Fatty acids of interest were identified by comparison with known standards and expressed as a percent of total fatty acids. The coefficient of variation for the RBC EPA + DHA assays was $<5 \%$.

\section{DATA ANALYSIS}

All data are reported as mean \pm SEM. The data were digitized $(1 \mathrm{kHz})$ and recorded using a Biopac MP-100 data acquisition system (Biopac Systems, Inc., Goleta, CA, USA). The HR and HRV data were averaged over $30 \mathrm{~s}$ intervals either during exercise or the coronary occlusion. ECG variables were averaged over the last five beats before and $60 \mathrm{~s}$ after the onset of the coronary occlusion. QT interval was corrected for changes in HR using Van de Water's correction formula $[\mathrm{QTc}=\mathrm{QT}-87(60 / \mathrm{HR}-1)]($ Van de Water et al., 1989).

The data were compared using ANOVA for repeated measures (NCSS statistical software, Kaysville, UT, USA). For example, the effects of $n-3$ PUFAs on the HR and HRV response to either submaximal exercise or the coronary artery occlusion at rest for the resistant or susceptible dogs were analyzed using a three factor ANOVA [pre-post (two levels) $\times$ dose (placebo vs. $n-3$ PUFA) $\times$ time (exercise seven levels or occlusion six levels) with repeated measures on two factors (pre-post and time)]. The effect of $n-3$ PUFA on ECG variables before and $60 \mathrm{~s}$ after coronary occlusion for the resistant or susceptible dogs were evaluated using a three factor [pre-post (two levels), dose (two levels), and occlusion time (two levels, before and $60 \mathrm{~s}$ after occlusion onset points)] ANOVA with repeated measure on two (pre-post and occlusion time) factors. Homogeneity of covariance (sphericity assumption, equal correlates between the treatments) was tested using Mauchly's test and, if appropriate, adjusted using HuynhFeldt correction. RBC and cardiac tissue lipid compositions were compared using a three factor ANOVA [group (VF+ vs. VF-), dose (placebo vs. $n-3$ PUFA), pre-post] with repeated measures on one factor (pre-post) or a two factor ANOVA [group (susceptible vs. resistant), dose (placebo vs. $n-3$ PUFA], respectively. If the $F$ value exceeded a critical value $(P<0.05)$, post hoc comparisons of the data were then made using Tukey-Kramer Multiple-Comparison Test.

\section{RESULTS \\ EFFECT OF $n-3$ PUFA ON RED BLOOD CELL AND CARDIAC TISSUE FATTY ACID CONTENT}

In agreement with previous studies (Billman et al., 2010; Billman, 2011), $n-3$ PUFA supplements elicited significant (dose effect, pre-post, and dose $\times$ pre-post interaction, all $P<10^{-6}$ ) increases in RBC membrane EPA, DHA, and the omega-3 index $(\mathrm{EPA}+\mathrm{DHA})$ as compared to the placebo treated animals (Table 1). Similar increases in EPA, DHA, and the omega-3 index were noted for both the susceptible and the resistant dogs (i.e., there were no significant group, group $\times$ dose interactions, or group $\times$ pre-post interactions). Thus, $n-3$ PUFA treatment increased RBC $n-3$ PUFA content to a similar extent in both the $\mathrm{VF}+$ and $\mathrm{VF}-$ dogs while lipid composition did not change during the 3-month study period in the placebo treated dogs in either group. In a similar manner, right atrial and left ventricular $n-3$ PUFA content was significantly higher $\left(P<10^{-6}\right)$ in $n-3$ PUFA compared to the placebo treated animals (Table 2). Once again these increases were similar in both the VF+ and VF- groups (i.e., there were no group or group $\times$ dose interactions for the either the LV or for the RA tissue).

\section{EFFECT OF $n-3$ PUFA ON BASELINE HEART RATE AND HEART RATE VARIABILITY}

The effect of $n-3$ PUFA or placebo on baseline (i.e., before a physiological challenge) HR and HRV are listed in Table 3. The $n-3$ PUFA treatment elicited significant reductions in $\operatorname{HR}(P<0.0002)$

Table 1 | Red blood cell omega-3 polyunsaturated fatty acid content.

\begin{tabular}{|c|c|c|c|c|c|c|}
\hline & \multicolumn{2}{|c|}{ EPA } & \multicolumn{2}{|c|}{ DHA } & \multicolumn{2}{|c|}{ Omega-3 index } \\
\hline & Pre & Post & Pre & Post & Pre & Post \\
\hline$V F-(n=4)$ & $0.17 \pm 0.01$ & $0.15 \pm 0.03$ & $0.30 \pm 0.05$ & $0.13 \pm 0.02$ & $0.47 \pm 0.04$ & $0.28 \pm 0.05$ \\
\hline$V F+(n=7)$ & $0.14 \pm 0.01$ & $0.20 \pm 0.02$ & $0.20 \pm 0.01$ & $0.24 \pm 0.05$ & $0.34 \pm 0.02$ & $0.41 \pm 0.04$ \\
\hline \multicolumn{7}{|l|}{$\boldsymbol{n}-3$ PUFA } \\
\hline $\mathrm{VF}+(n=22)$ & $0.20 \pm 0.01$ & $2.79 \pm 0.33^{*+}$ & $0.27 \pm 0.05$ & $2.52 \pm 0.19^{*+}$ & $0.52 \pm 0.07$ & $5.31 \pm 0.45^{*+}$ \\
\hline
\end{tabular}

All values are expressed of \% of the total lipid content. EPA, eicosapentaenoic acid; DHA, docosahexaenoic acid; omega-3 index, EPA +DHA, *P $<0.01$ pre vs. post, $+P<0.01$ placebo vs. $n-3$ PUFA (omega-3 polyunsaturated fatty acids). There were no significant differences between VF- (resistant to ventricular fibrillation) and $V F+$ (susceptible to ventricular fibrillation) for either the placebo or $n-3$ PUFA treated animals. 
Table 2 | Cardiac tissue omega-3 polyunsaturated fatty acid content.

\begin{tabular}{llll}
\hline \multicolumn{2}{c}{ EPA } & DHA & Omega-3 index \\
\hline \multicolumn{2}{c}{ RIGHT ATRIUM } & \\
$\begin{array}{l}\text { Placebo } \\
\text { VF- }\end{array}$ & $0.11 \pm 0.08$ & $0.16 \pm 0.10$ & $0.27 \pm 0.18(n=3)$ \\
VF+ & $0.36 \pm 0.12$ & $0.58 \pm 0.17$ & $0.91 \pm 0.25(n=6)$ \\
$n-3$ PUFA & & & \\
VF- & $2.04 \pm 0.31^{*}$ & $2.89 \pm 0.33^{*}$ & $4.92 \pm 0.59^{*}(n=23)$ \\
VF+ & $1.62 \pm 0.25^{*}$ & $2.80 \pm 0.37^{*}$ & $4.41 \pm 0.61^{*}(n=22)$ \\
LEFT VENTRICLE & & \\
Placebo & & & \\
VF- & $0.12 \pm 0.06$ & $0.19 \pm 0.06$ & $0.31 \pm 0.11(n=3)$ \\
VF+ & $0.34 \pm 0.05$ & $0.45 \pm 0.10$ & $0.80 \pm 0.13(n=6)$ \\
$n-3$ PUFA & & & \\
VF- & $2.98 \pm 0.30^{*}$ & $3.00 \pm 0.17^{*}$ & $5.98 \pm 0.43^{*}(n=23)$ \\
VF+ & $2.27 \pm 0.28^{*}$ & $2.80 \pm 0.20^{*}$ & $4.41 \pm 0.43^{*}(n=21)$ \\
\end{tabular}

All values are expressed of $\%$ of the total lipid content. EPA, eicosapentaenoic acid; DHA, docosahexaenoic acid; omega-3 index, EPA +DHA, ${ }^{*} P<0.01$ placebo vs. n-3 PUFA (omega-3 polyunsaturated fatty acids). There were no significant differences between VF- (resistant to ventricular fibrillation) and VF+ (susceptible to ventricular fibrillation) for either the placebo or $n-3$ PUFA treated animals.

that were accompanied by a corresponding increase in the HF component $(\mathrm{HF}, 0.24-1.04 \mathrm{~Hz})$ of R-R interval variability $(P<0.002)$ in both the VF- and VF+ animals. However, total beat-to-beat variability as measured by the $\mathrm{SD}$ of $\mathrm{R}-\mathrm{R}$ variability was not altered by $n-3$ PUFA treatment. There were no differences noted between the VF+ and VF- dogs (no significant group effect or group $\times$ pre-post interactions). In contrast, placebo treatment did not alter either baseline HR, HF, or SD in either the VF- or in the VF+ groups (Table 3 ). Thus, $n-3$ PUFA treatment provoked changes in resting HR and HRV in both VF- and VF+ dogs that were consistent with either an enhanced cardiac vagal regulation (Task Force of the European Society of Cardiology and the North American Society of Pacing and Electrophysiology, 1996; Berntson et al., 1997; Billman, 2009, 2011) or a change in baseline intrinsic rate (Verkerk et al., 2009; Billman and Harris, 2011).

\section{EFFECT OF $n-3$ PUFA ON THE ECG VARIABLES, HEART RATE, AND HEART RATE VARIABILITY RESPONSE TO ACUTE MYOCARDIAL ISCHEMIA}

The effects of the placebo and the $n-3$ PUFA treatment on ECG parameters at baseline and in response to coronary artery occlusion for the VF+ and VF- dogs are listed in Table 4. The coronary occlusion provoked significant increases in $\mathrm{HR}$ (both VF+ and $\mathrm{VF}-, P<10^{-6}$ ) and the descending portion of the T wave (VF+ only, $P<0.00003)$, a marker of the dispersion of repolarization (Yan and Antzelevitch, 1998; Opthof et al., 2007) while eliciting decreases in $\mathrm{PR}$ interval (VF+, $P<0.0001 ; \mathrm{VF}-, P<0.002)$. No other ECG variable was affected by the ischemia. The $n-3$ PUFA treatment (but not placebo) elicited significant reductions in $\mathrm{HR}(\mathrm{VF}+, P<0.04$; VF- $P<0.04)$ and increases in $\mathrm{PR}$ inter$\operatorname{val}(\mathrm{VF}+, P<0.02 ; \mathrm{VF}-, P<0.03)$, changes that were maintained during the coronary occlusion. Interestingly, pre-occlusion QTc interval increased in both the placebo and $n-3$ PUFA treatment
Table 3 | Effect of dietary omega-3 polyunsaturated fatty acids on heart rate and heart rate variability.

\begin{tabular}{|c|c|c|}
\hline & Pre-treatment & Post-treatment \\
\hline \multicolumn{3}{|c|}{ HEART RATE (BEATS/MIN) } \\
\hline \multicolumn{3}{|l|}{ VF+ } \\
\hline Placebo $(n=9)$ & $122.4 \pm 4.7$ & $121.6 \pm 4.20$ \\
\hline$n-3$ PUFA $(n=22)$ & $123.3 \pm 4.5$ & $112.6 \pm 4.2^{*}$ \\
\hline \multicolumn{3}{|l|}{ VF- } \\
\hline Placebo $(n=8)$ & $123.3 \pm 5.2$ & $127.0 \pm 6.0$ \\
\hline$n-3$ PUFA $(n=23)$ & $122.3 \pm 4.1$ & $106.9 \pm 3.8^{*}$ \\
\hline \multicolumn{3}{|c|}{ HIGH FREQUENCY $(0.24-1.04 \mathrm{~Hz})$ VARIABILITY $\left(\mathrm{In} \mathrm{ms}^{2}\right)$} \\
\hline \multicolumn{3}{|l|}{$\mathrm{VF}+$} \\
\hline Placebo & $6.7 \pm 0.3$ & $6.3 \pm 0.5$ \\
\hline$n-3$ PUFA & $7.0 \pm 0.3$ & $7.5 \pm 0.2^{*}$ \\
\hline \multicolumn{3}{|l|}{$V F-$} \\
\hline Placebo & $7.0 \pm 0.3$ & $6.7 \pm 0.4$ \\
\hline$n-3$ PUFA & $6.7 \pm 0.3$ & $7.7 \pm 0.3^{*}$ \\
\hline \multicolumn{3}{|c|}{ R-R INTERVAL SD (ms) } \\
\hline \multicolumn{3}{|l|}{ VF+ } \\
\hline Placebo & $60.2 \pm 6.9$ & $67.8 \pm 10.2$ \\
\hline$n-3$ PUFA & $59.0 \pm 6.6$ & $69.8 \pm 5.8$ \\
\hline \multicolumn{3}{|l|}{$V F-$} \\
\hline Placebo & $69.6 \pm 8.2$ & $68.8 \pm 9.4$ \\
\hline$n-3$ PUFA & $65.9 \pm 10.3$ & $74.8 \pm 6.3$ \\
\hline
\end{tabular}

${ }^{*} P<0.01$ Pre-treatment vs. Post-treatment; $n-3$ PUFA, omega-3 polyunsaturated fatty acids; VF+, susceptible to ventricular fibrillation; $V F-$, resistant to ventricular fibrillation.

$(\mathrm{VF}+, P<0.02 ; \mathrm{VF}-, P<0.0001)$ at the end of the 3 -month treatment period as compared to values obtained before the treatment began.

The effects of placebo and the $n-3$ PUFA treatment on the HR and HRV (HF only) response to the acute myocardial ischemia are displayed for VF+ and VF- dogs in Figures 1 and 2, respectively. In agreement with previous studies (Collins and Billman, 1989; Halliwill et al., 1998; Houle and Billman, 1999; Billman, 2006; Billman and Kukielka, 2006), the coronary occlusion significantly increased HR (occlusion time effect, $P<10^{-6}$ ) and decreased HRV (both HF and SD, occlusion time effect, $P<10^{-6}$ ) in the placebo and in the $n-3$ PUFA treated animals. HR was significantly lower (pre-post, VF- $P<0.0004$; VF+ $P<0.02$ ), and both HF (pre-post, VF- $P<0.0001$; VF $+P<0.03$ ) and $\mathrm{SD}$ (data not shown pre-post, $\mathrm{VF}-P<0.009$; VF $+P<0.05$ ) were higher during the coronary occlusion after $n-3$ PUFA treatment as compared to values obtained prior to the treatment. However, the absolute change in these variables induced by myocardial ischemia (VF-: $\Delta \mathrm{HR}$ pre-treatment $23.5 \pm 4.3 \mathrm{vs.}$ post-treatment $19.7 \pm 4.6$ beats/min, $\Delta \mathrm{HF}$ pre $-3.5 \pm 0.4$ vs. post $-2.5 \pm 0.5 \mathrm{ln} \mathrm{ms}{ }^{2} ; \Delta S D$ pre $-39.3 \pm 10.5$ vs. post $-25.9 \pm 6.5 \mathrm{~ms}$; $\mathrm{VF}+: \Delta \mathrm{HR}$ pre $41.2 \pm 5.8$ vs. post $35.5 \pm 6.8$ beats $/ \mathrm{min}, \Delta \mathrm{HF}$ pre $-4.4 \pm 0.5$ vs. post $-3.6 \pm 0.6 \ln \mathrm{ms}^{2} ; \Delta \mathrm{SD}$ pre $-39.0 \pm 7.9$ vs. post $-32.8 \pm 7.0 \mathrm{~ms}$ ) was not altered by the $n-3$ PUFA treatment (i.e., there were no significant pre-post $\times$ time interactions for either group). Thus, $n-3$ PUFA treatment elicited a similar downward shift in resting HR and an upward shift in the resting 
Table 4 | Effect of dietary omega-3 fatty acids on ECG parameters at baseline and during coronary artery occlusion.

\begin{tabular}{|c|c|c|c|c|}
\hline & \multicolumn{2}{|c|}{ Pre-treatment } & \multicolumn{2}{|c|}{ Post-treatment } \\
\hline & Control & Occlusion & Control & Occlusion \\
\hline \multicolumn{5}{|c|}{ HEART RATE (BEATS/MIN) } \\
\hline \multicolumn{5}{|l|}{$\mathrm{VF}+$} \\
\hline Placebo & $125.6 \pm 7.1$ & $172.9 \pm 13.6^{*}$ & $124.6 \pm 8.4$ & $168.6 \pm 16.4^{*}$ \\
\hline$n-3$ PUFA & $126.7 \pm 5.1$ & $163.9 \pm 7.3^{*}$ & $113.9 \pm 4.3^{\#}$ & $147.3 \pm 6.9^{* \#}$ \\
\hline \multicolumn{5}{|l|}{$V F-$} \\
\hline Placebo & $122.8 \pm 7.2$ & $148.1 \pm 12.9^{*}$ & $125.4 \pm 9.3$ & $144.7 \pm 10.3^{*}$ \\
\hline$n-3$ PUFA & $128.6 \pm 4.7$ & $146.7 \pm 6.0^{*}$ & $116.2 \pm 4.1^{\#}$ & $139.4 \pm 5.9^{*}$ \\
\hline \multicolumn{5}{|c|}{ PR INTERVAL (ms) } \\
\hline \multicolumn{5}{|l|}{ VF+ } \\
\hline Placebo & $91.2 \pm 4.9$ & $77.6 \pm 6.2^{*}$ & $98.8 \pm 5.5$ & $83.8 \pm 2.6^{*}$ \\
\hline$n-3$ PUFA & $95.3 \pm 3.5$ & $87.1 \pm 3.5^{*}$ & $104.9 \pm 3.4^{\#}$ & $96.8 \pm 3.5^{* \#}$ \\
\hline \multicolumn{5}{|l|}{$V F-$} \\
\hline Placebo & $99.6 \pm 3.7$ & $83.6 \pm 4.2^{*}$ & $102.3 \pm 4.1$ & $99.4 \pm 5.0^{*}$ \\
\hline$n-3$ PUFA & $98.7 \pm 3.4$ & $88.6 \pm 3.7^{*}$ & $103.4 \pm 3.2$ & $95.4 \pm 4.2^{*}$ \\
\hline \multicolumn{5}{|c|}{ QRS DURATION (ms) } \\
\hline \multicolumn{5}{|l|}{$\mathrm{VF}+$} \\
\hline Placebo & $77.2 \pm 4.3$ & $78.2 \pm 4.7$ & $79.6 \pm 3.9$ & $79.1 \pm 2.1$ \\
\hline$n-3$ PUFA & $82.8 \pm 1.6$ & $79.0 \pm 2.1$ & $82.0 \pm 1.1$ & $80.9 \pm 1.6$ \\
\hline \multicolumn{5}{|l|}{$V F-$} \\
\hline Placebo & $83.4 \pm 2.9$ & $81.1 \pm 2.9$ & $88.3 \pm 1.6$ & $86.3 \pm 2.0$ \\
\hline$n-3$ PUFA & $80.0 \pm 1.9$ & $79.4 \pm 2.0$ & $82.5 \pm 1.5$ & $82.1 \pm 1.5$ \\
\hline \multicolumn{5}{|c|}{ QTc INTERVAL (ms) } \\
\hline \multicolumn{5}{|l|}{$\mathrm{VF}+$} \\
\hline Placebo & $245.6 \pm 5.0$ & $248.0 \pm 5.2$ & $263.8 \pm 5.4^{\#}$ & $250.7 \pm 5.4$ \\
\hline$n-3$ PUFA & $256.2 \pm 3.6$ & $257.9 \pm 5.8$ & $272.4 \pm 3.3^{\#}$ & $261.9 \pm 3.6^{\#}$ \\
\hline \multicolumn{5}{|l|}{$V F-$} \\
\hline Placebo & $251.0 \pm 7.5$ & $255.1 \pm 5.4$ & $278.0 \pm 3.7^{\#}$ & $268.3 \pm 5.4^{\#}$ \\
\hline$n-3$ PUFA & $252.4 \pm 3.1$ & $248.6 \pm 3.2$ & $270.2 \pm 3.9^{\#}$ & $268.3 \pm 4.7^{\#}$ \\
\hline \multicolumn{5}{|c|}{$\boldsymbol{T}_{P E A K}-\boldsymbol{T}_{E N D}$ (CORRECTED; ms) } \\
\hline \multicolumn{5}{|l|}{$\mathrm{VF}+$} \\
\hline Placebo & $89.1 \pm 6.2$ & $97.7 \pm 6.3^{*}$ & $87.11 \pm 3.5$ & $110.3 \pm 7.3^{*}$ \\
\hline$n-3$ PUFA & $87.7 \pm 3.2$ & $103.6 \pm 3.7^{*}$ & $89.5 \pm 2.9$ & $105.4 \pm 4.5^{*}$ \\
\hline \multicolumn{5}{|l|}{$V F-$} \\
\hline Placebo & $86.9 \pm 4.5$ & $92.7 \pm 5.1$ & $90.7 \pm 4.8$ & $91.3 \pm 7.1$ \\
\hline$n-3$ PUFA & $88.6 \pm 3.1$ & $85.6 \pm 4.6$ & $89.0 \pm 4.5$ & $92.4 \pm 4.6$ \\
\hline
\end{tabular}

${ }^{*} P<0.01$ control vs. coronary artery occlusion (60 s after occlusion onset); ${ }^{\#} P<0.01$ Pre-treatment vs. Post-treatment; $n-3$ PUFA, omega-3 polyunsaturated fatty acids.

Heart rate correction: $Q T C=Q T-87(60 / H R-1) ; T_{\text {peak }}-T_{\text {end }}$ (corrected $)=T_{\text {peak }}-$ $T_{\text {end }}-87(60 / H R-1)$ Nan de Water et al., 1989); VF+, susceptible to ventricular fibrillation, $V F-$, resistant to ventricular fibrillation.

HRV in both VF+ and VF- animals but did not alter the magnitude of the change in these variables that was induced by the coronary artery occlusion (i.e., the response to the coronary occlusion per se was not affected by the treatment) in either group.

In contrast, the placebo treatment did not alter the HR, HF, or $\mathrm{SD}$ (i.e., there were no significant pre-post effects) response to the coronary occlusion in the VF- dogs. In the VF+ dogs, the coronary occlusion elicited larger increases in HR (pre-post, $P<0.01$ )

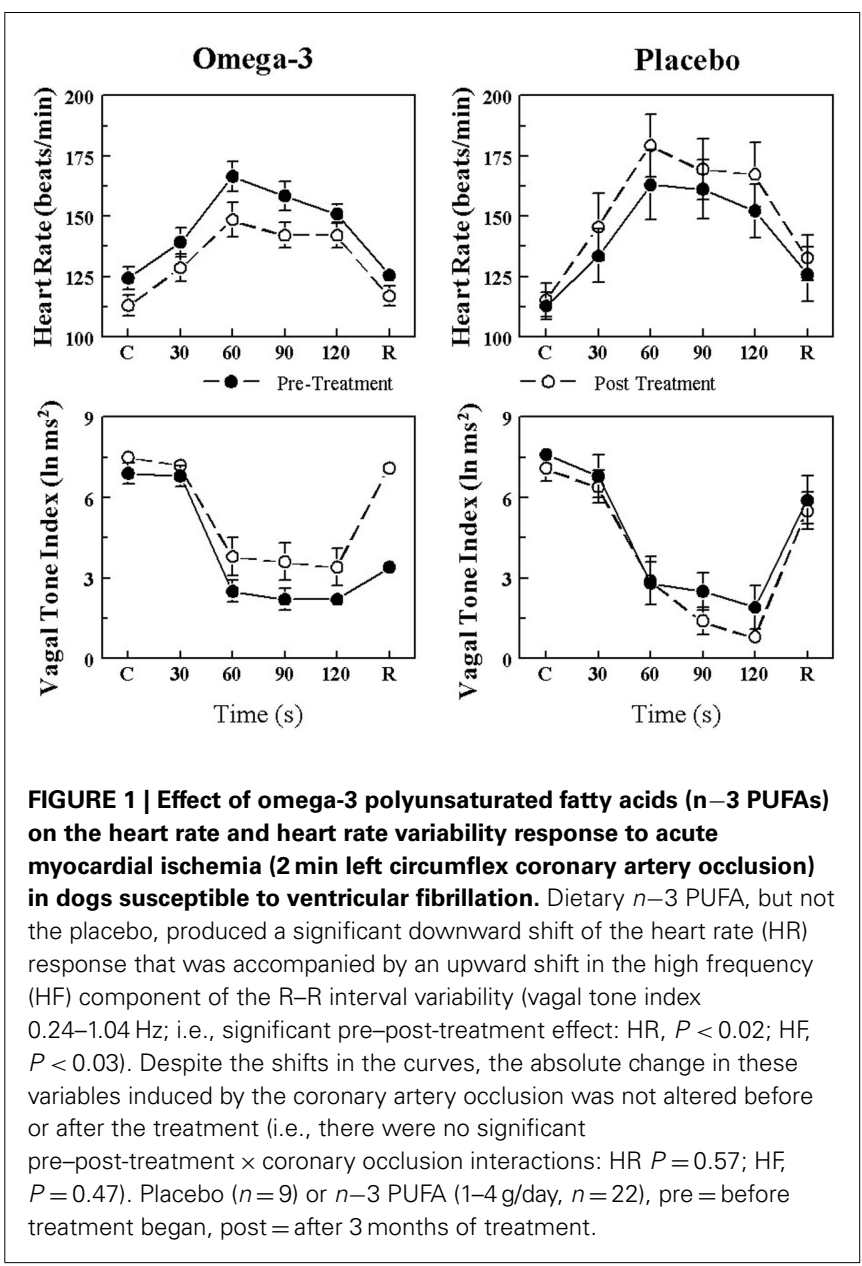

at the end of the 3-month study period, but neither HF nor SD (no significant pre-post effect) was altered by the placebo treatment. As was noted following $n-3$ PUFA treatment, the absolute change in these variables induced by myocardial ischemia was also similar (i.e., there were no significant pre-post $\times$ occlusion interactions) in both VF- and VF+ animals before and at the end of the placebo treatment.

\section{EFFECT OF $n-3$ PUFA ON THE HEART RATE AND HEART RATE VARIABILITY RESPONSE TO SUBMAXIMAL EXERCISE}

The HR and HRV response to submaximal exercise before and after 3 months of placebo or $n-3$ PUFA treatment are displayed in Figure $3(\mathrm{VF}+)$ and Figure $4(\mathrm{VF}-)$. As one would predict, exercise provoked large increases in HR (exercise level effect, $P<10^{-6}$ ) that were accompanied by large reductions in HRV (exercise level effect, $P<10^{-6}$ ) in all four groups. HR was significantly lower (pre-post effect: VF-, $P<0.05 ; \mathrm{VF}+, P<0.04$ ), and both $\mathrm{HF}$ (pre-post: $\mathrm{VF}-, P<0.02 ; \mathrm{VF}+, P<0.02$ ) and $\mathrm{SD}$ (data not shown pre-post: VF-, $P<0.0004$; VF+, $P<0.005)$ were higher during exercise after $n-3$ PUFA treatment as compared to values obtained prior to the treatment. In contrast, $\mathrm{HR}, \mathrm{HF}$, and SD were not altered (no significant pre-post effects) by the placebo treatment. The change in $\mathrm{HR}(\mathrm{VF}-$-, pre-treatment $62.4 \pm 6.7$ vs. post-treatment $66.6 \pm 5.5 ; \mathrm{VF}+$, pre $65.8 \pm 5.3$ vs. post $59.8 \pm 6.3$ beats $/ \mathrm{min}), \mathrm{HF}$ 

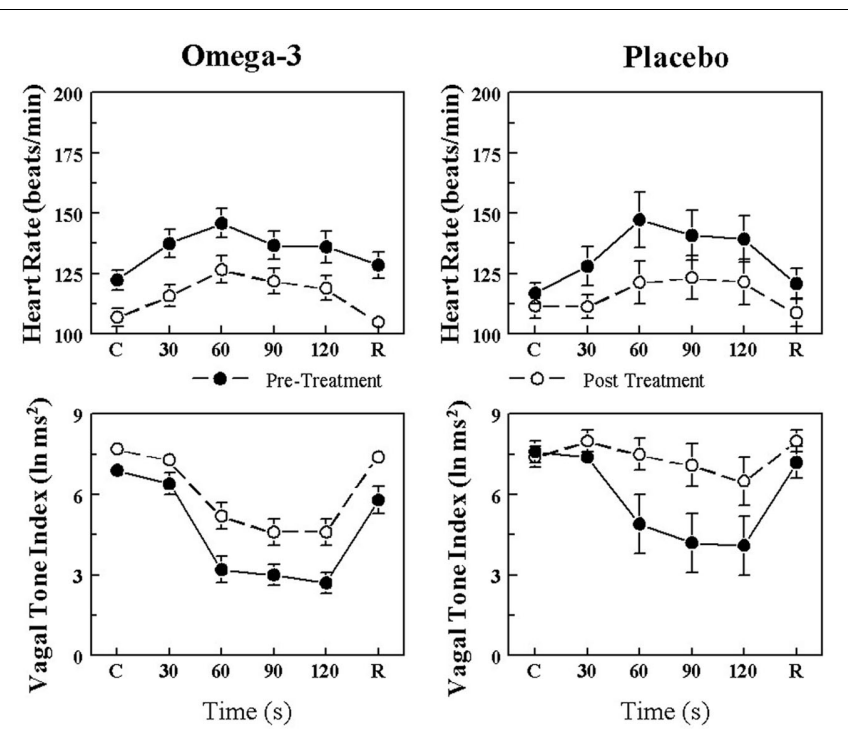

FIGURE 2 | Effect of omega-3 polyunsaturated fatty acids ( $n-3$ PUFAs) on the heart rate and heart rate variability response to acute myocardial ischemia ( 2 min left circumflex coronary artery occlusion) in dogs resistant to ventricular fibrillation. Dietary $n-3$ PUFA, but not the placebo, produced a significant downward shift of the heart rate (HR) response that was accompanied by an upward shift in the high frequency (HF) component of the R-R interval variability (vagal tone index 0.24-1.04 Hz; i.e., significant pre-post-treatment effect: $\mathrm{HR}, P<0.004$; $\mathrm{HF}$ $P<0.001$ ). Despite the shifts in the curves, the absolute change in these variables induced by the coronary artery occlusion was not altered before or after the treatment (i.e., there were no significant pre-post-treatment $\times$ coronary occlusion interactions: HR, 0.27; HF, $P=0.07)$. Placebo $(n=8)$ or $n-3$ PUFA ( $1-4 \mathrm{~g} /$ day, $n=23)$, pre = before treatment began, post $=$ after 3 months of treatment.

(VF-, pre $-4.9 \pm 0.3$ vs. post $-5.0 \pm 0.2 ; \mathrm{VF}+$, pre $-6.2 \pm 0.5$ vs. post $-6.3 \pm 0.5 \ln \mathrm{ms}^{2}$ ), and $\mathrm{SD}$ (VF-, pre $-44.5 \pm 4.2$ vs. post $60.3 \pm 9.3 ; \mathrm{VF}+,-36.5 \pm 4.7$ vs. post $-47.7 \pm 6.3 \mathrm{~ms})$ provoked by exercise were not affected by the $n-3$ PUFA treatment (i.e., there were no significant pre-post $\times$ exercise level interactions). Thus, $n-3$ PUFA produced a similar shift in the pre-exercise values of HR, HF, and SD in both VF+ and VF - animals and, further, the magnitude of the change in these variables that was induced by exercise was not altered by $n-3$ PUFA for either group. In other words, the response to exercise per se was not affected by the treatment.

\section{DISCUSSION}

The present study investigated the effects of dietary $n-3$ PUFA (1$4 \mathrm{~g}$ /day for 3 months) on HR and HRV (both at baseline and during physiological stress - exercise or acute myocardial ischemia) in dogs with healed myocardial infarction that were known to be either susceptible or resistant to VF. The major findings of the study are as follows: first, and in agreement with previous studies (Harris et al., 2004, 2006; Billman et al., 2010; Billman and Harris, 2011), the $n-3$ PUFA treatment elicited increases in both $\mathrm{RBC}$ and cardiac (right atrial and left ventricular) tissue DHA and EPA content. Second, consistent with previous observations (Billman and Harris, 2011) n-3 PUFA, but not placebo, treatment
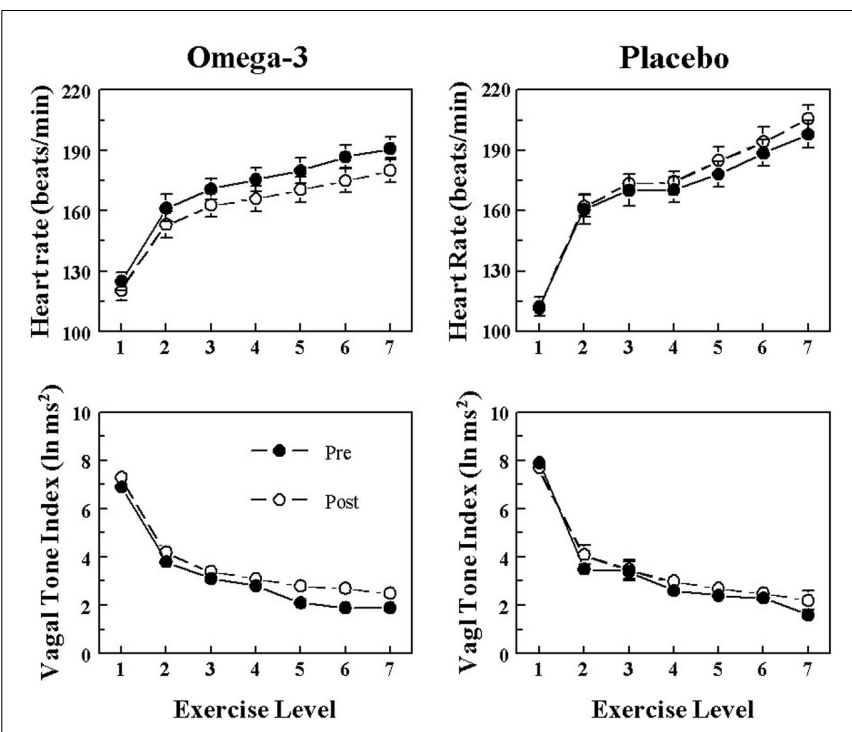

FIGURE 3 | Effect of omega-3 polyunsaturated fatty acids ( $n-3$ PUFAs) on the heart rate and heart rate variability response to submaximal exercise in dogs susceptible to ventricular fibrillation. Dietary $n-3$ PUFA, but not the placebo, produced a significant downward shift of the heart rate $(\mathrm{HR})$ response curve that was accompanied by an upward shift in the high frequency (HF) component of the R-R interval variability (vagal tone index $0.24-1.04 \mathrm{~Hz}$; i.e., significant pre-post effect: $\mathrm{HR}, P<0.04$; HF, $P<0.02$ ). Despite the shifts in the curves, the absolute change in these variables induced by the exercise was not altered before or after the treatment (i.e., there were no significant pre-post-treatment $\times$ exercise interactions: $\mathrm{HR}, P=0.68 ; \mathrm{HF}, P=0.45)$. The data were averaged over the last $30 \mathrm{~s}$ of given exercise level. Exercise levels are as follows: $1=0 \mathrm{kph}$ and $0 \%$ grade; $2=4.8 \mathrm{kph}$ and $0 \%$ grade; $3=6.4 \mathrm{kph}$ and $0 \%$ grade; $4=6.4 \mathrm{kph}$ and $4 \%$ grade; $5=6.4 \mathrm{kph}$ and $8 \%$ grade; $6=6.4 \mathrm{kph}$ and $12 \%$ grade; $7=6.4 \mathrm{kph}$ and $16 \%$ grade. Pre = before placebo $(n=9)$ or $n-3$ PUFA $(1-4 \mathrm{~g} /$ day, $n=22)$ treatment began, post $=$ after 3 months of treatment.

elicited reductions in baseline HR, increases in HRV and increases in PR interval. No other ECG parameter was affected by the $n-3$ PUFA treatment. Thus, although the acute application of $n-3$ PUFAs have been shown to decrease action potential duration in isolated cardiomyocytes (Verkerk et al., 2006; den Ruijter et al., 2008, 2010), long-term $n-3$ PUFA treatment did not alter global indices of ventricular repolarization in the present study. Interestingly, QT interval corrected for a HR increased at the end of the 3-month treatment period in both the placebo and the $n-3$ PUFA treated groups, data consistent with a time-dependent electrophysiological remodeling that results as a consequence of myocardial infarction. Third, although the peak values obtained during the stimulus were lower after $n-3$ PUFA treatment as compared to values reached before the treatment began, the absolute magnitude of the change in HR and HRV provoked by either exercise or acute myocardial ischemia was not altered by $n-3$ PUFA treatment and was similar to that recorded for the placebo groups. In other words, the $n-3$ PUFA treatment produced parallel shifts in the response to either exercise or the coronary occlusion due to changes in baseline (pre-challenge) HR and HRV. Fourth, the changes in both the baseline HR and HRV and the changes induced in these variables by a physiological challenge were nearly identical 

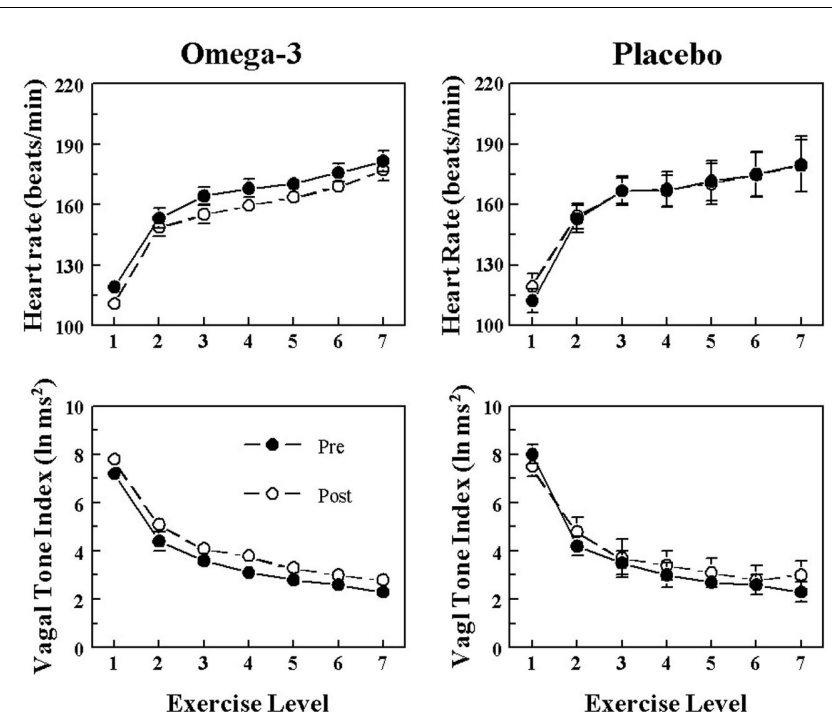

FIGURE 4 | Effect of omega-3 polyunsaturated fatty acids (n-3 PUFAs) on the heart rate and heart rate variability response to submaximal exercise in dogs resistant to ventricular fibrillation. Dietary $n-3$ PUFA, but not the placebo, produced a significant downward shift of the heart rate (HR) response curve that was accompanied by an upward shift in the high frequency (HF) component of the R-R interval variability (vagal tone index $0.24-1.04 \mathrm{~Hz}$; i.e., significant pre-post effect: $\mathrm{HR}, P<0.05 ; \mathrm{HF}, P<0.02$ ). Despite the shifts in the curves, the absolute change in these variables induced by the exercise was not altered before or after the treatment (i.e., there were no significant pre-post-treatment $\times$ exercise interactions: HR, $P=0.67 ; \mathrm{HF}, P=0.88$ ). The data were averaged over the last $30 \mathrm{~s}$ of given exercise level. Exercise levels are as follows: $1=0 \mathrm{kph}$ and $0 \%$ grade; $2=4.8 \mathrm{kph}$ and $0 \%$ grade; $3=6.4 \mathrm{kph}$ and $0 \%$ grade; $4=6.4 \mathrm{kph}$ and $4 \%$ grade; $5=6.4 \mathrm{kph}$ and $8 \%$ grade; $6=6.4 \mathrm{kph}$ and $12 \%$ grade; $7=6.4 \mathrm{kph}$ and $16 \%$ grade. Pre $=$ before placebo $(n=8)$ or $n-3$ PUFA ( $1-4 \mathrm{~g} /$ day, $n=23$ ) treatment began, post $=$ after 3 months of treatment.

in the susceptible and resistant dogs. These data suggest that despite significantly different initial responses (VF+ animals had a higher HR and lower HRV during exercise or myocardial ischemia as compared to the VF- dogs), $n-3$ PUFA treatment produced similar changes in HR and HRV in dogs that either exhibited VF or had no arrhythmias induced by myocardial ischemia.

\section{EFFECT OF $n$-3 PUFA ON RESTING HEART RATE AND HEART RATE VARIABILITY}

In agreement with the present study, a number of clinical (Christensen et al., 1999; Christensen and Schmidt, 2007; Carney et al., 2010; Christensen, 2011) and experimental studies (Laustiola et al., 1986; Kang and Leaf, 1994; Billman et al., 2010; Billman and Harris, 2011; Mayyas et al., 2011) report that $n-3$ PUFA ingestion or acute intravenous administration (Billman et al., 1994) lower HR and increase HRV, suggestive of an increase in cardiac parasympathetic regulation. However, there are also studies in which $n-3$ PUFA failed to alter either HRV or other measures of autonomic function (Russo et al., 1995; Geelen et al., 2003; Hamaad et al., 2006), such as baroreceptor sensitivity (Geelen et al., 2003). Furthermore, even in the studies that reported a positive action of $n-3$ PUFAs on HR or HRV, the effect was often quite small (Mozaffarian et al., $2005,2006,2008)$. For example, a meta-analysis of 30 trials found that fish oil supplements (approximately $3.5 \mathrm{~g} /$ day of EPA + DHA) reduced baseline HR by 2.5 beats/min (Mozaffarian et al., 2005), while Mozaffarian et al. (2008) reported that individuals with the highest fish consumption ( $\geq 5$ meals per weak) only exhibited $1.5 \mathrm{~ms}$ greater HRV compared to those with the lowest fish consumption. Although this difference was statistically significant, such a small change in resting HRV is not likely to be physiologically relevant. Indeed, these investigators calculated that only a $1.1 \%$ reduction in the relative risk for sudden cardiac death could be associated with this very modest increase in HRV (Mozaffarian et al., 2008). However, these small changes could have important consequences if they are maintained during a physiological stressor such as exercise or acute myocardial ischemia. Reductions in HR would reduce metabolic demand placed on the heart particularly when oxygen supply is compromised by coronary artery lesions/obstructions. The resulting better match between oxygen supply and oxygen demand would, indirectly, decrease the risk for adverse cardiac events associated with myocardial ischemia. In fact, individuals with the lowest resting HRs also exhibited the lowest long-term (>20 years) mortality rate (Jouven et al., 2009). Furthermore, the beneficial effects of beta-adrenergic receptor antagonists, the most effective anti-arrhythmic medication, have been attributed to the negative chronotropic actions of these drugs (Held and Yusuf, 1993). However, it has been recently reported that $n-3$ PUFA treatment not only failed to prevent malignant arrhythmias in VF+ animals, but actually increased ventricular tachyarrhythmias in VF- dogs (Billman et al., 2012). Thus, $n-3$ PUFA mediated reductions in HR were not sufficient to protect against malignant arrhythmias.

\section{EFFECT OF $n-3$ PUFA ON HEART RATE AND HEART VARIABILITY RESPONSE TO MYOCARDIAL ISCHEMIA}

As expected from previous studies (Collins and Billman, 1989; Halliwill et al., 1998; Houle and Billman, 1999; Billman, 2006; Billman and Kukielka, 2006), the coronary artery occlusion elicited a robust HR increase that was accompanied by a rapid withdrawal in parasympathetic regulation as indicated by the decline in both total R-R interval variability (SD) and the HF component of R-R interval variability. However, despite alterations in pre-occlusion HR and HRV, the cardiac response to coronary artery occlusion was not altered by the $n-3$ PUFA treatment in either the VF+ or the VF- groups. The $n-3$ PUFA treatment produced parallel shifts in the coronary occlusion response curves (due to changes in the pre-occlusion HR and HRV) but the magnitude of the change in these variables was not altered by the $n-3$ PUFA treatment. As the robust autonomic response to the coronary occlusion was not altered, the changes in pre-ischemic HR and HRV induced by the $n-3$ PUFA may be insufficient to prevent malignant changes in the cardiac rhythm. In fact, as was previously noted, long-term $n-3$ PUFA treatment failed to prevent ischemically induced arrhythmias in the same canine model of sudden cardiac as used in the present study (Billman et al., 2012). These results are analogous to those obtained following treatment with low doses of the cholinergic antagonist atropine (Kottmeier and Gravenstein, 1968; Casadei et al., 1993; De Ferrari et al., 1993; Hull et al., 1995; Halliwill et al., 1998). Using the same canine model of myocardial infarction, low dose atropine decreased baseline HR and increased HRV but, 
as in the present study, did not alter the response to myocardial ischemia (Halliwill et al., 1998). This intervention also failed to prevent the induction of VF (Hull et al., 1995; Halliwill et al., 1998). In marked contrast, however, exercise training not only improved resting HR and HRV but also dramatically reduced the response to coronary occlusion and completely suppressed the formation of malignant ventricular tachyarrhythmias (Billman and Kukielka, 2006). When considered together these results strongly suggest that, in order to be effective, an intervention must enhance cardiac parasympathetic regulation during myocardial ischemia; resting changes alone may be insufficient to protect against malignant arrhythmias.

\section{EFFECT OF $\boldsymbol{n}-3$ PUFA ON HEART RATE AND HEART VARIABILITY RESPONSE TO EXERCISE}

In agreement with previous human (O'Keefe et al., 2006; Ninio et al., 2008; Peoples et al., 2008; Buckley et al., 2009) and animal studies (Billman and Harris, 2011), dietary $n-3$ PUFA treatment also elicited similar parallel shifts in HR and HRV during exercise but did not alter the response in placebo treated dogs. Furthermore, $n-3$ PUFA provoked nearly identical changes in $\mathrm{HR}$ and HRV in both the VF+ and VF- animals. In contrast, an endurance exercise training program (10 weeks treadmill running) both improved resting HR and HRV and attenuated the cardiac response to submaximal exercise in the same canine model as was used in the present study (Billman and Kukielka, 2006, 2007). Unlike $n-3$ PUFA treatment, exercise training also elicited much larger reductions in $\mathrm{HR}$ and increases in $\mathrm{HRV}$ in $\mathrm{VF}+$ as compared to VF- animals (Billman and Kukielka, 2006, 2007). Thus, exercise training, in marked contrast to $n-3$ PUFA treatment, can elicit larger changes (improvements) in HRV in the animals with more pronounced impairments in cardiac autonomic function than in the dogs with more modest changes in autonomic regulation following myocardial infarction.

\section{LIMITATIONS OF THE STUDY}

In the present study cardiac vagal nerve activity was not directly recorded. Cardiac parasympathetic regulation was only indirectly evaluated using non-invasive markers of HRV. Although a number of studies provide strong evidence that beat-to-beat fluctuation in HR reflect corresponding changes in cardiac parasympathetic regulation (Task Force of the European Society of Cardiology and the North American Society of Pacing and Electrophysiology, 1996; Berntson et al., 1997; Parati et al., 2006; Billman, 2009, 2011), an accurate assessment of nerve activity can only be obtained from direct nerve recordings. As such, HRV data should always be interpreted with care.

Second, previous studies demonstrate that ventricular function is not altered by myocardial infarction in the canine model used in the present study (Billman et al., 1985, 2010; Houle et al., 2001). As such, one might speculate that the potential benefits of dietary $n-3$ PUFA on cardiac autonomic regulation could be more obvious in individuals with more severe cardiac impairment. A more severe impairment in autonomic regulation, particularly during physiological challenges, is consistently noted in VF+ as compared to VF- animals, yet $n-3$ PUFA treatment yielded similar changes in both groups in the present study. Thus, $n-3$ PUFA did not elicit a larger response in the animals with the greatest autonomic impairment. As the effects of $n-3$ PUFA treatment were nearly identical in both VF+ and VF- dogs, these data suggest that perhaps, rather than altering cardiac autonomic regulation, these lipids exert their actions via changes in the intrinsic pacemaker rate. Indeed recent in vitro (Verkerk et al., 2009) and in vivo (Billman and Harris, 2011) studies demonstrate that $n-3$ PUFA can reduce intrinsic pacemaker rate most likely via action on the pacemaker current $\left(I_{\mathrm{f}}\right)$. Further investigation will be required to determine the physiological mechanisms responsible for $n-3$ PUFA mediated changes in HR.

Third, selecting human-equivalent doses of $n-3$ PUFA for animal studies is challenging. The average $n-3$ PUFA dose (adjusted for body surface area) was equivalent to about $5 \mathrm{~g} /$ day (VF-, $5.34 \pm 0.12$ and $\mathrm{VF}+, 5.17 \pm 0.13 \mathrm{~g} /$ day) in human subjects. As such, this dose is higher than the $1-\mathrm{g} /$ day dose that has been used in most interventional studies (e.g., Marchioli et al., 2002). However, it is very close to the dose of prescription $n-3$ PUFA (4 g/day, Lovaza ${ }^{\circledR}$, GlaxoSmithKline) used to treat hypertriglyceridemia (Von Schacky, 2006) and doses up to $8 \mathrm{~g} /$ day $n-3$ PUFA have been used to evaluate the effect of $n-3$ PUFA on HRV in human subjects (Peoples et al., 2008). Furthermore, the doses used in the present study yielded RBC membrane EPA + DHA levels that were associated with a significant reduction in the risk for sudden death in epidemiological studies (Siscovick et al., 1995; Albert et al., 2002). Specifically, Albert et al. (2002) found that a mean $\mathrm{RBC}$ concentration of $6.9 \%$ was associated with a $90 \%$ reduction in the risk for sudden death, a value that compares favorably to that obtained in the present study (mean RBC concentration, $\mathrm{VF}-$, $5.5 \pm 0.3 \%$ and $\mathrm{VF}+, 5.4 \pm 0.5 \%$, range $2.3-10.7 \%$ ).

Finally, although dog and man exhibit a similar cardiac autonomic regulation (Scher et al., 1972), species differences could also contribute to response differences. One must always use caution when extrapolating results between species.

\section{CONCLUSION}

In the present study, dietary $n-3$ PUFA (DHA + EPA ethyl esters, 1-4 g/day for 3 months) elicited similar reductions in baseline HR that were accompanied by similar increases in HRV in dogs that were susceptible or resistant to VF. However, and in contrast to endurance exercise training (Billman and Kukielka, 2006, 2007), $n-3$ PUFA treatment did not alter the robust autonomic response (identical increases in HR and decreases in HRV before and after treatment) induced by either exercise or, more importantly, by myocardial ischemia in either group of dogs. As both dogs that were either resistant or susceptible to malignant tachyarrhythmias exhibited similar changes in baseline HR and HRV and in the response to physiological challenges, it seems unlikely that changes in HR and HRV are solely responsible for the putative cardiovascular benefits of these lipids.

\section{ACKNOWLEDGMENTS}

The author wishes to thank Raven Morgan, and Anita McKenzie for their technician assistance and to Dr. William S. Harris for performing the blood and tissue lipid analyses. The author also wishes to thank GlaxoSmithKline for generously providing the $n-3$ PUFA ethyl ester and placebo capsules for this study. This work was supported by National Heart, Lung and Blood Institute Grants HL086700. 


\section{REFERENCES}

Albert, C. M., Campos, H., Stamfer, M. J., Ridker, P. M., Mason, J. E., Willet, W. C., and Ma, J. (2002). Blood levels of long-chin n-3 fatty acids and the risk of sudden death. N. Engl. J. Med. 346, 1113-1118.

Berntson, G. G., Bigger, J. T., Eckberg, D. L., Grossman, P., Kaufmann, P. G., Malik, M., Nagaraja, H. K., Proges, S. W., Saul, J. P., Stone, P. H., and van der Molen, M. W. (1997). Heart rate variability: origins, methods, and interpretive caveats. Pyschophysiology 34, 623-648.

Billman, G. E. (2006). A comprehensive review and analysis of 25 years of data from an in vivo canine model of sudden cardiac death: implications for future anti-arrhythmic drug development. Pharmacol. Ther. 111, 808-835.

Billman, G. E. (2009). Cardiac autonomic neural "remodeling" and susceptibility to sudden cardiac death: effect of endurance exercise training. Am. J. Physiol. Heart Circ. Physiol. 297, H1171-H1193.

Billman, G. E. (2011). Heart variability - a historical perspective. Front. Physiol. 2:86. doi:10.3389/fphys.2011.00086

Billman, G. E., and Dujardin, J.-P. (1990). Dynamic changes in cardiac vagal tone as measured by timeseries analysis. Am. J. Physiol. Heart Circ. Physiol. 258, H896-H902.

Billman, G. E., Hallaq, H., and Leaf, A. (1994). Prevention of ischemiainduced ventricular fibrillation by omega-3 fatty acids. Proc. Natl. Acad. Sci. U.S.A. 91, 4427-4430.

Billman, G. E., and Harris, W. S. (2011). Effect of dietary omega-3 fatty acids on heart rate and the heart rate variability responses to myocardial ischemia or exercise. Am. J. Physiol. Heart Circ. Physiol. 300, H2288H2299.

Billman, G. E., Harris, W. S., Carnes, C. A., Adamson, P. B., Vanoli, E., and Schwartz, P. J. (2012). Dietary omega-3 fatty acids and susceptibility to ventirualr fibrillation: lack of protection and a proarrythmic effect. Circ. Arrhythm. Electrophysiol. doi:10.1161/CIRCEP.111.966739 (in press).

Billman, G. E., and Hoskins, R. S. (1989). Time-series analysis of heart rate variability during submaximal exercise. Evidence for reduced cardiac vagal tone in animals susceptible to ventricular fibrillation. $\mathrm{Circu}$ lation 80, 146-157.

Billman, G. E., and Kukielka, M. (2006). Effects of endurance exercise training on heart rate variability and susceptibility to sudden cardiac death: protection is not due to enhanced cardiac vagal regulation. J. Appl. Physiol. 100, 896-906.

Billman, G. E., and Kukielka, M. (2007). Effect of endurance exercise training on the heart rate onset and heart rate recovery responses to submaximal exercise in animals susceptible to ventricular fibrillation. J. Appl. Physiol. 102, 231-240.

Billman, G. E., Nishijima, Y., Belevych, A. E., Terentyev, D., Xu, Y., Haizlip, K. M., Monasky, M. M., Hiranandani, N., Harris, W. S., Gyorke, S., Carnes, C. A., and Janssen, P. M. L. (2010). Effects of dietary omega-3 fatty acids on ventricular function in dogs with healed myocardial infarctions. Am. J. Physiol. Heart Circ. Physiol. 298, H1219-H1228.

Billman, G. E., Schwartz, P. J., Gagnol, J. P., and Stone, H. L. (1985). The cardiac response to submaximal exercise in dogs susceptible to sudden cardiac death. J. Appl. Physiol. 59, 890-897.

Billman, G. E., Schwartz, P. J., and Stone, H. L. (1982). Baroreceptor reflex control of heart rate: a predictor of sudden death. Circulation 66, 874-880.

Bligh, E. G., and Dyer, W. J. (1959). A rapid method for total lipid extraction and purification. Can. J. Biochem. Physiol. 37, 911-917.

Buckley, J. D., Burgess, S., Murphy, K. J., and Howe, P. R. C. (2009). DHA-rich fish oil lowers heart rate during submaximal exercise in elite Australian Rules footballers. J. Sci. Med. Sport. 12, 503-507.

Carney, R. M., Freedland, K. E., Stein, P. K., Steinmeyer, B. C., Harris, W. S., Rubin, E. H., Krone, R. J., and Rich, W. W. (2010). Effect of omega3 fatty acids on heart rate variability in depressed patients with coronary heart disease. Psychosom. Med. 72, 748-754.

Casadei, B., Pipillis, A., Sessa, F., Conway, J., and Sleight, P. (1993). Low doses of scopolamine increase cardiac vagal tone in the acute phase of myocardial infarction. Circulation 88, 353-357.

Christensen, J. H. (2011). Omega3 fatty acids and heart rate variability. Front. Physiol. 2:84. doi:10.3389/fphys.2011.00084

Christensen, J. H., Christensen, M. S., Dyerberg, J., and Schmidt, E. B. (1999). Heart rate variability and fatty acid content in blood cell membranes: a dose-response study with n-3 fatty acids. Am. J. Clin. Nutr. 70, 331-337.
Christensen, J. H., and Schmidt, E. B. (2007). Autonomic nervous system, heart rate variability and n-3 fatty acids. J. Cardiovasc. Med. 8(Suppl. 1), S19-S22.

Collins, M. N., and Billman, G. E. (1989). Autonomic response to coronary occlusion in animals susceptible to ventricular fibrillation. Am. J. Physiol. Heart Circ. Physiol. 257, H1886-H1894.

De Ferrari, G. M., Mantica, M., Vanoli, E., Hull, S. S. Jr., and Schwartz, P. J. (1993). Scopolamine increases vagal tone and vagal reflexes in patients after myocardial infarction. J. Am. Coll. Cardiol. 22, 1327-1334.

den Ruijter, H. M., Berecki, G., Verkerk, A. O., Bakker, D., Baartscheer, A., Schumacher, C. A., Belterman, C. N., de Jonge, N., Fiolet, J. W., Brower, I. A., and Coronel, R. (2008). Acute administration of fish oil inhibits triggered activity in isolated myocytes from rabbits and patients with heart failure. Circulation 117, 536-544.

den Ruijter, H. M., Verkerk, A. O., and Coronel, R. (2010). Incorporated fish oil fatty acids prevent action potential shortening induced by circulating fish oil fatty acids. Front. Physiol. 1:149. doi:10.3389/fphys.2010.00149

Di Stasi, D., Bernasconi, R., Marchioli, R., Marfisi, R. M., Rossi, G., Tognoni, G., and Tacconi, M. T. (2004). Early modifications of fatty acid composition in plasma phospholipids, platelets and mononucleates of healthy volunteers after low doses of n-3 polyunsaturated fatty acids. Eur. J. Clin. Pharmacol. 60 183-190.

Geelen, A., Zock, P. L., Swenne, C. A., Brouwer, I. A., Schouten, E. G., and Katan, M. B. (2003). Effect of n3 fatty acids on heart rate variability and baroreflex sensitivity in middle-aged subjects. Am. Heart J. 146, E4.

Halliwill, J. R., Billman, G. E., and Eckberg, D. L. (1998). Effect of a vagomimetic atropine dose on canine cardiac vagal tone and susceptibility to sudden cardiac death. Clin. Auton. Res. 8, 155-164.

Hamaad, A., Lee, W. K., Lip, G. Y. H., and MacFadyen, R. J. (2006). Oral omega-3 PUFA therapy (Omacor) has no impact on indices of heart rate variability in stable post myocardial infarction patients. Cardiovasc. Drugs Ther. 20, 359-364.

Harris, W. S., Gonzles, M., Laney, N., Sastre, A., and Borkon, A. M. (2006). Effects of omega-3 fatty acids on heart rate in cardiac transplant recipients. Am. J. Cardiol. 98, 1393-1395.

Harris, W. S., Sands, S. A., Windsor, S. L., Ali, H. A., Stevens, T. L., Magalski, A., Porter, C. B., and Borkon, A. M. (2004). Omega-3 fatty acids in cardiac biopsies from heart transplantation patients: correlation with erythrocytes and response to supplementation. Circulation 110, 1645-1649.

Held, P. H., and Yusuf, S. (1993). Effects of beta-blockers and $\mathrm{Ca} 2^{+}$channel blockers in acute myocardial infarction. Eur. Heart J. 14 (Suppl. F), 18-25.

Houle, M. S., Altschuld, R. A., and Billman, G. E. (2001). Enhanced in vivo and in vitro contractile responses in $\beta_{2}$-adreneric receptor stimulation in dogs susceptible to lethal arrhythmias. J. Appl. Physiol. 91, 1627-1637.

Houle, M. S., and Billman, G. E. (1999). Low-frequency component of the heart rate variability spectrum: a poor marker of sympathetic activity. Am. J. Physiol. Heart Circ. Physiol. 276, H215-H223.

Hull, S. S. Jr., Vanoli, E., Adamson, P. B., De Ferrari, G. M., Foreman, R. D., and Schwartz, P. J. (1995). Do increases in markers of vagal activity imply protection from sudden death? The case of scopolamine. Circulation 91, 2516-2519.

Jouven, X., Empana, J. P., Escolano, S., Buyck, J. F., Tafflet, M., Desnos, M., and Ducimetiere, P. (2009). Relation of heart rate at rest and longterm ( $>20$ years) death rate in initially healthy middle-aged men. Am. J. Cardiol. 103, 279-283.

Kang, J. X., and Leaf, A. (1994). Effects of long-chain polyunsaturated fatty acids on the contraction of neonatal rat cardiac myocytes. Proc. Natl. Acad. Sci. U.S.A. 91, 9886-9890.

Kottmeier, C. A., and Gravenstein, J. S. (1968). The parasympathomimetic activity of atropine and atropine methylbromide. Anesthesiology 29, 1125-1133.

Laustiola, K., Salo, M. K., and MetsäKetelä, T. (1986). Altered physiological responses and decreased cyclic AMP levels in rat atria after dietary cod liver oil supplementation and its possible association with $\mathrm{n} 3 / \mathrm{n} 6$ fatty acid ratio. Biochim. Biophys. Acta 889, 59-79.

Marchioli, R., Barzi, F., Bomba, E., Chieffo, C., Di Gregorio, D., Di Mascio, R., Franzosi, M. G., Geraci, E., Levantesi, G., Maggioni, A. P., Mantini, L., Marfisi, R. M., Mastrogiuseppi, G., Mininni, N., Nicolisi, G. L., Santini, M., Schweiger, C., Tavazzi, L., Tognoni, G., Tucci, C., and 
Valagussa, F. (2002). Early protection against sudden death by $n-3$ polyunsaturated fatty acids after myocardial infarction: time-course analysis of the results of the Gruppo Italiano per lo Studio della Sopravvivenza nell'Infarto Miocardico (GISSI)-Prevenzione. Circulation 105, 1897-1903.

Mayyas, F., Sakurai, S., Ram, R., Rennison, J. H., Hwang, E.-S., Castel, L., Lovano, B., Brennan, M.-L., Bibus, D., Lands, B., Barnard, J., Chung, M. K., and Van Wagoner, D. R. (2011). Dietary $\omega 3$ fatty acids modulate the substrate for post-operative atrial fibrillation in a canine cardiac surgery model. Cardiovasc. Res. 89, 852-861.

Morrison, W. R., and Smith, L. M. (1964). Preparation of fatty acid methyl esters and dimethylacetals from lipids with boron fluoride-methanol. J. Lipid Res. 5, 600-608.

Mozaffarian, D., Geelen, A., Brouwer, I. A., Geleijnse, J. M., Zock, P. L., and Katan, M. B. (2005). Effect of fish oil on heart rate in humans: metaanalysis of randomized controlled trials. Circulation 112, 1945-1952.

Mozaffarian, D., Prineas, R. J., Stein, P. K., and Siscovick, D. S. (2006). Dietary fish and n-3 fatty acid intake and cardiac electrocardiographic parameters in humans. J. Am. Coll. Cardiol. 48, 478-484.

Mozaffarian, D., Stein, P. K., Prineas, R. J., and Siscovick, D. S. (2008). Dietary Fish $\omega-3$ fatty acid consumption and heart rate variability in US adults. Circulation 117, 1130-1137.

Ninio, D. M., Hill, A. M., Howe, P. R., Buckley, J. D., and Saint, D. A. (2008). Docosahexaenoic acid-rich fish oil improves heart variability and heart rate responses to exercise in overweight adults. Br. J. Nutr. 100, 1097-1103.

O'Keefe, J. H. Jr., Abuissa, H., Sastre, A., Steinhaus, D. M., and Harris, W. S. (2006). Effects of omega3 fatty acids on resting heart rate, heart rate recovery after exercise, and heart rate variability in men with healed myocardial infarctions and depressed ejection fraction. Am. J. Cardiol. 97, 1127-1130.

Opthof, T., Coronel, R., WilmsSchopman, F. J. G., Plotnikov, A. N, Shlapakova, I. N., Danilo, P. Jr., Rosen, M. R., and Janse, M. J. (2007). Dispersion of repolarization in canine ventricle and electrocardiographic $\mathrm{T}$ wav: Tp-e interval does not reflect transmural dispersion. Heart Rhythm 4, 341-348.

Parati, G., di Rienzo, M., Castiglioni, P., Mancia, G., Taylor, J. A., and Studinger, P. (2006). Point: counterpoint: cardiovascular variability is/is not an index of autonomic control of circulation. J. Appl. Physiol. 101, 676-682.

Peoples, G. E., McLennan, P. L., Howe, P. R. C., and Groeller, H. (2008). Fish oil reduces heart rate and oxygen consumption during exercise. J. Cardiovasc. Pharmacol. 52, 540-547.

Porges, S. W. (1986). "Respiratory sinus arrhythmia: physiological basis, quantitative methods and clinical implications," in Cardiac, Respiratory, and Cardiosomatic Psychophysiology, eds P. Grossman, K. H. L. Janssen, and D. Vaitl (New York: Plenum), 101-115.

Russo, C., Olivieri, O., Girelli, D., Azzini, M., Stanzial, A. M., Guarini, P., Friso, S., De Franceschi, L., and Corrocher, R. (1995). Omega-3 polyunsaturated fatty acid supplements and ambulatory blood pressure monitoring parameters in patients with mild hypertension. J. Hypertens. 13, 1823-1826.

Scher, A. M., Ohm, W. W., Bumgarner, K., Boynton, R., and Young, A. C. (1972). Sympathetic and parasympathetic control of heart rate in the dog, baboon and man. Fed. Proc. 31, 1219-1225.

Schwartz, P. J., Billman, G. E., and Stone, H. L. (1984). Autonomic mechanisms in ventricular fibrillation due to acute myocardial ischemia during exercise in dogs with healed myocardial infarction: an experimental model for sudden cardiac death. Circulation 69, 790-800.

Siscovick, D. S., Raghunathan, T. E., King, I., Weinmann, S., Wicklund, K. G., Albright, J., Bouberg, V., Arbogast, P., Smith, H., Kushi, L. H., Cobb, L. A., Copass, M. K., Psaty, B., Lemaitre, R., Retzlaff, B. Childs, M., and Knopp, R. H. (1995). Dietary intake and cell membrane levels of long-chain n-3 polyunsaturated fatty acids and the risk of primary cardiac arrest. JAMA 274 1363-1367.

Task Force of the European Society of Cardiology and the North American Society of Pacing and Electrophysiology. (1996). Heart rate variability: standards of measurement, physiological interpretation, and clinical use. Circulation 93, 1043-1065.

Van de Water, A., Verheyen, J., Xhonnex, R., and Reneman, R. S. (1989). An improved method to correct QT interval of the electrocardiogram fro changes in heart rate. J. Pharmacol. Methods 22, 207-217.

Verkerk, A. O., den Ruijter, H. M. Bourier, J., Boukens, B. J., Brouwer, I. A., Wilders, R., and Coronel, R. (2009). Dietary fish oil reduces pacemaker current and heart rate in rabbit. Heart Rhythm 6, 1485-1492.
Verkerk, A. O., van Ginneken, A. C., Berecki, G., den Ruijter, H. M., Schumacher, C. A., Veldkamp, M. W., Casini, S., Opthof, T., Hovenier, R., Fiolet, J. W., Zock, P. L., and Coronel, R. (2006). Incorporated sarcolemmal fish oil fatty acids shorten pig ventricular action potentials. Cardiovasc. Res. 70, 509-520.

Von Schacky, C. (2006). A review of omega-3 ethyl esters for the cardiovascular prevention and treatment of increased blood triglyceride levels. Vasc. Health Risk Manag. 2, 251-262. Yan, G. X., and Antzelevitch, C. (1998). Cellular basis for the normal $\mathrm{T}$ wave and the electrocardiographic manifestations of the long-QT syndrome. Circulation 98, 1928-1936.

Conflict of Interest Statement: The author declares that the research was conducted in the absence of any commercial or financial relationships that could be construed as a potential conflict of interest.

Received: 09 December 2011; paper pending published: 06 March 2012; accepted: 12 March 2012; published online: 27 March 2012.

Citation: Billman GE (2012) Effect of dietary omega-3 polyunsaturated fatty acids on heart rate and heart rate variability in animals susceptible or resistant to ventricular fibrillation. Front. Physio. 3:71. doi: 10.3389/fphys.2012.00071 This article was submitted to Frontiers in Cardiac Electrophysiology, a specialty of Frontiers in Physiology.

Copyright (c) 2012 Billman. This is an open-access article distributed under the terms of the Creative Commons Attribution Non Commercial License, which permits non-commercial use, distribution, and reproduction in other forums, provided the original authors and source are credited. 